\title{
Arthroscopic surgery was not effective for relieving pain or improving function in osteoarthritis of the knee
}

\author{
Moseley JB, O' Malley K, Petersen NJ, et al. A controlled trial of arthroscopic surgery for osteoarthritis of the knee. N EnglJ \\ Med 2002;347:81-8.
QUESTION: In patients with osteoarthritis of the knee, is arthroscopic surgery effective for relieving pain and improving function?

\section{Design}

Randomised (allocation concealed*), blinded (patients and outcome assessors),* placebo controlled trial with 2 years of follow up.

\section{Setting}

A Veterans Affairs medical centre in Houston, Texas, USA.

\section{Patients}

180 patients who were $\leq 75$ years of age (mean age $52 \mathrm{y}$, 93\% men), had osteoarthritis of the knee as defined by the American College of Rheumatology, reported at least moderate knee pain (scored $\geq 4$ on a visual analogue scale of $0-10$ ) despite maximal medical treatment for $\geq 6$ months, and had not received arthroscopy in the previous 2 years. Exclusion criteria were severity grade $\geq 9$ (maximum 12), severe deformity, or serious medical problems. Follow up was $89 \%$ at 1 year and $91 \%$ at 2 years.

\section{Intervention}

After stratification for severity of osteoarthritis, patients were allocated to 1 of 3 groups: lavage $(n=61)$, debridement $(n=59)$, or placebo $(n=60)$. In the lavage group, the joint was lavaged with $\geq 10$ litres of fluid. Anything that could be flushed out through arthroscopic cannulas was removed, and unstable meniscal tears were removed. Debridement consisted of lavage with $\geq 10$ litres of fluid, shaving rough articular cartilage, removing loose debris, and trimming torn or degenerated meniscal fragments. Lavage and debridement were done under general anaesthesia with endotracheal intubation. The placebo group received three $1 \mathrm{~cm}$ skin incisions under a short acting tranquiliser and an opioid and spontaneously breathed oxygen-enriched air.

Source of funding:

Department of Veterans Affairs.

For correspondence: $\operatorname{Dr} N$ P Wray, Baylor College of Medicine,

Houston, TX, USA. nuray@bcm.tmc.edu

Abstract and commentary also appear in ACP Journal Club.

Lavage or debridement v placebo for osteoarthritis of the kneet

\begin{tabular}{|c|c|c|c|c|}
\hline \multirow[b]{2}{*}{ Outcome } & \multirow[b]{2}{*}{ Lavage } & \multicolumn{2}{|l|}{ Mean score } & \multirow{2}{*}{$\begin{array}{l}\text { Mean score difference } \\
(95 \% \mathrm{Cl})\end{array}$} \\
\hline & & Debridement & Placebo & \\
\hline \multirow[t]{2}{*}{ Pain at 1 year (KSPS) } & 54.8 & & 48.9 & $5.9(-2.0$ to 13.8$)$ \\
\hline & & 51.7 & 48.9 & $2.8(-5.9$ to 11.5$)$ \\
\hline \multirow[t]{2}{*}{ Pain at 2 years (KSPS) } & 53.7 & & 51.6 & $2.1(-6.9$ to 11.1$)$ \\
\hline & & 51.4 & 51.6 & $0.2(-8.8$ to 9.2$)$ \\
\hline
\end{tabular}

tKSPS $=$ Knee-Specific Pain Scale (scores 0-100 [most severe]). All differences are statistically nonsignificant.

\section{Main results}

Lavage and debridement did not differ from placebo for pain in the study knee at 1 or 2 years (table) or for any secondary outcome measure.

\section{Conclusion}

In patients with osteoarthritis of the knee, arthroscopic surgery did not relieve pain or improve function more than a placebo procedure.

*See glossary.

\section{COMMENTARY}

Many surgeons have recognised the uncertainty surrounding the efficacy of arthroscopic lavage and debridement for the painful osteoarthritic knee. Most clinicians, in my experience, have concluded that a randomised controlled trial with a sham placebo might resolve that uncertainty but would probably be unethical.

The study by Moseley et al is comprehensively reported and referenced and seems to have been carefully done. The methods used for analysis are appropriate. The study found no evidence that lavage or debridement was superior to placebo in this patient group. Furthermore, the $95 \%$ confidence intervals for most comparisons did not include a level considered to constitute the minimal important difference, which instead of being prespecified was calculated post hoc from available literature and trial data.

The argument for ethical approval may have focused around equipoise and patient competence. Primum non nocere ("first, do no harm") is breached by this trial; sham surgery is not a harmless placebo, even though it involved only three $1 \mathrm{~cm}$ skin incisions under a light anaesthetic regimen. But if the single surgeon who performed all procedures was in a state of individual equipoise (ie, had a genuine uncertainty about the therapeutic merits of each treatment) and the participants, having signed a declaration accepting the possibility of a sham procedure, were competent, informed, and in equipoise, an acceptable argument for ethical approval might emerge. The fact that $44 \%$ of eligible patients declined to participate suggests that the information given was clear enough for them at least; those who chose to participate may have been less informed or driven by altruism.

The fact that so many potential participants declined raises the possibility of selection bias, which may threaten generalisability. The authors note that, compared with those who declined, participants were younger, more likely to be white, and had more severe arthritis. It would have been useful to see follow up data on those who declined to be randomised but who subsequently had either lavage or debridement. Nevertheless, this study makes a case for questioning the value of arthroscopic lavage and debridement in active men younger than 65 years of age with osteoarthritis of the knee.

William J Gillespie, MBChB, FRACS Hull York Medical School York, UK 